\title{
SOIL REHABILITATION TO INCREASE PRODUCTIVITY BOYOLALI AGRICULTURE BY FAST DETECTION CURCUMARVEL
}

\author{
Dwi Rahmasari Fatmawati, Annisa Kurniawati, Arsyadani Tri Nastiti Nur, Eli Budia \\ Pamilujeng, Praditya Rizqi Novanto, Ratih Ineke Wati \\ Universitas Gadjah Mada \\ dwirahmasari@mail.ugm.ac.id
}

\begin{abstract}
Boyolali regency is one of the areas that has decreased rice productivity. The decline was caused by acidic soil conditions coupled with a lack of awareness of farmers and support of facilities and infrastructure. The goals of this program are to empower farmer groups to become land rehabilitation agents through early detection of CurcuMarvel using tumerics. Soil detectors can be developed using turmeric. Turmeric is easily found to be a solution to the problem of the detection of soil conditions. Target is the Sari Tani farmer group located in Suyudan village, Boyolali regency. The empowerment program is carried out by: (1) transferring information using educational videos; (2) shows the detection of soil acidity in one of the farmers' rice fields; (3) land rehabilitation efforts by applying dolomite, manure, and biological fertilizers in the pilot plot; and (4) turmeric cultivation training. Results of this program are: (1) farmers know that their paddy land is acidic; (2) their awareness of the effects of soil acidity is increasing; (3) farmers carry out soil rehabilitation; (4) farmers have turmeric centers near rice fields and (5) increasing productivity of agriculture.
\end{abstract}

Keywords: Acidic Soil, CurcuMarvel, Empowerment, Soil Detector, Turmeric

Received 20February 2020 Accepted 23 May 2020 Available online 24 June 2020

\section{INTRODUCTION}

Boyolali regency is one of the centers of lowland rice production in Central Java Province, with average productivity reaching 5.4 tons/ha in 2018. According to the Central Statistics Agency, Boyolali regency has decreased productivity, one of which is caused by a decrease in the ability of the soil to support production rice in paddy fields. In the last three years, rice production decreased by $10 \%$, from 270,809 tons in 2015 to 267,809 tons in 2018 (BPS, 2019). During this time, the handling of the phenomenon of decreased productivity of lowland rice has always been synonymous with the management of Plant Pests (OPT). As a result, the handling of other factors causing a decline in productivity of lowland rice is ignored. One of them is the degradation of paddy soil conditions due to excessive fertilization and continuous irrigation. In the peasant community's environment, even the perception arises that when the soil is fertilized and watered continuously, the soil will be more fertile. Thus, make the nutrient availability decreased and potentially cause soil $\mathrm{pH}$ became acidic [1].

The productivity decline of paddy rice in Boyolali, one of which occurred in the Suyudan village. Based on the results of measurements of soil $\mathrm{pH}$ at several sample points, this location has a high degree of acidity $(\mathrm{pH}=5.5)$, so it has the potential to reduce the productivity of agricultural products. To improve these conditions, it is necessary to empower farmers to detect the degree of acidity $(\mathrm{pH})$ and return it to normal conditions $(\mathrm{pH}=7)$. The most accurate way to find out soil acidity is to use a $\mathrm{pH}$ meter. However, many farmers do not have appropriate tools due to high prices and lack of knowledge about the importance of the degree of soil acidity. 
CurcuMarvel is an appropriate technology to discover the acidity of the soil using turmeric as a detection tool. Turmeric is a spice that is easy to find and familiar to farmers, so its use to detect the acidity of paddy soils can be a suitable solution. Turmeric is also easy to cultivate in your yard. The implementation of this program will help farmers in Suyudan hamlet in solving the problem of measuring soil $\mathrm{pH}$. The CurcuMarvel program can also be the first step in soil rehabilitation efforts to increase the productivity of lowland rice.

Farmer empowerment is an effort to help farmers improve their quality of life, based on their power. Community empowerment can be interpreted as a development counseling process, where community independence is key [2]. The empowerment of rice farmers in the CurcuMarvel program is an effort to change the farmers' knowledge, attitudes, and skills. So they could be aware, willing, and able to detect soil acidity to increase the productivity of lowland rice. This program is carried out in conjunction with soil rehabilitation efforts by administering dolomite, organic fertilizer, and biological fertilizers according to the required dosage based on soil $\mathrm{pH}$ values. For the sustainability of the program, training in the cultivation of turmeric in the yard is carried out.

Interest execution Program CurcuMarvel in Suyudan hamlet, village of Kiringan, district of Boyolali, is empowering farmer groups to become a driving agent soil rehabilitation with early detection CurcuMarvel. Increasing farmers' knowledge, attitudes, and skills in measuring the acidity $(\mathrm{pH})$ of the soil using turmeric is the first step for farmers to rehabilitate paddy soils. This program is expected to be a reference for the government in fulfilling agricultural facilities and infrastructure according to standards.

\section{RESEARCH METHOD(S)}

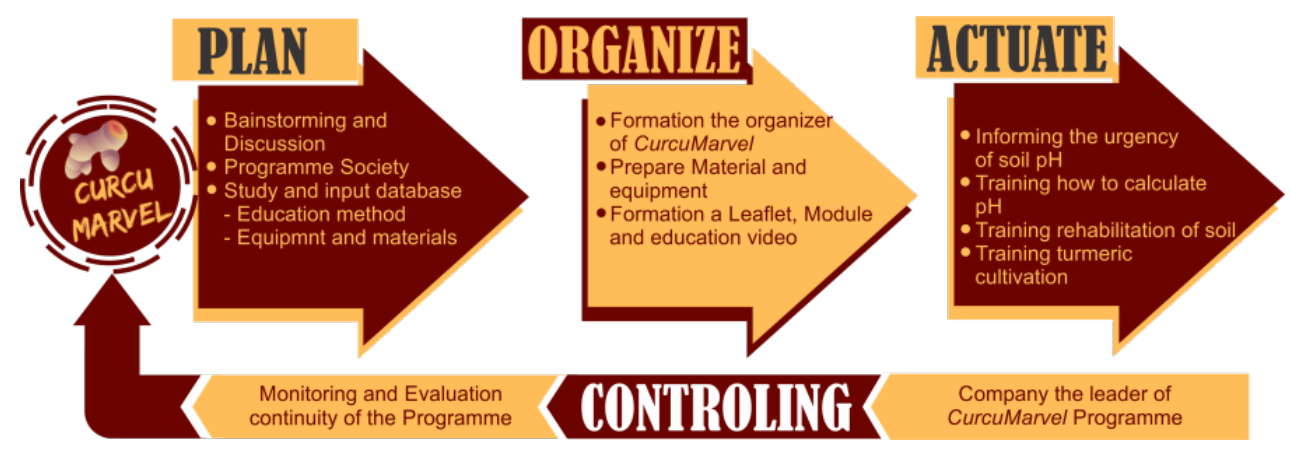

Figure 1. Method and implementation of CurcuMarvel program

This empowerment of rice farmers through the CurcuMarvel program is carried out in Suyudan village, Boyolali district, in April-July 2019. This program consists of three principal activities: (1) detect the acidity of the soil by using turmeric; (2) conducting soil rehabilitation using dolomite, organic fertilizer, and biological fertilizer; and (3) training turmeric in the soil. Implementation of the program is done through 4 (four) main processes: plan, organize, actuate, and control, which can be seen in Figure 1. Program implementation uses a participatory approach to maximize the empowerment process. The learning method used in empowering rice farmers is a combination of lectures, demonstration plots, and discussion methods. The target of the program was the representative of the management and members of the Sari Tani farmers group in Suyudan hamlet, Kiringan village, Boyolali district. The total number of farmers participating in the program is ten people.

\section{FINDINGS AND DISCUSSION}

Turmeric rhizome contains about $10 \%$ curcuminoid, curcumin $1-5 \%$, and the rest consists of demectosicurcumin and bisdemetoksikurkumin. Curcumin is a dyestuff that is biogenetically 
derived from phenylalanine, malonic acid, and citric acid [3]. Curcumin dyes are yellow-orange crystals, insoluble in ether, soluble in oil, in brownish-red alkali, while in acid yellow [4]. Turmeric is a rhizomatous herbaceous perennial plant (Curcuma longa) of the ginger family [5]. Curcumin is a coloring constituent of turmeric that giving yellow pigmentation. Characterisation of the immobilised curcumin reagent also showed promising results, hence a good potential for use as a sensing reagent for an optical $\mathrm{pH}$ sensor [6].

\section{Suyudan Village}

Suyudan village is a village in Kiringan village, Boyolali district, Boyolali regency, Central Java province. The population of Kiringan village is 5,224 people, consisting of 2,588 men and 2,636 women. The area of Kiringan village is $83.90 \mathrm{~km}^{2}$. Topographically, it is a low-lying area with hills and mountains. It is located at an average altitude of 700 meters above sea level. It also has an extensive agricultural paddy field with a wet and humid land structure. Most of the livelihoods of Kiringan village residents are farmers. They are joined in the farmer group called "Sari Tani." This farmer group has 40 members. Most of the farmers participated in this farmers' group are Hodge or farm workers, which leased the land from the landowner for $300-400 \mathrm{~m}^{2}$ area.

\section{Planning Activities}

1. Brainstorming and discussions

Brainstorming and discussions were held at the Kiringan village head's office and attended by the Kiringan Village Head, Secretary, and ten members of the Sari Tani farmer group. The objective of these activities was to increase the productivity of paddy fields. This method is carried out using a participatory approach that involves actively targeting the community to formulate their problems and needs. At this stage, farmers are invited to have dialogues related to land conditions, issues in the field, and demands on the land as provisions to formulate problems and solutions that will be realized through the CurcuMarvel program.

All parties present at the discussion agreed to apply for the CurcuMarvel program in paddy fields in the Suyudan village. These results indicate the need for the people of Suyudan village to rehabilitate their land. Thus, an organizational empowerment program through members of the Sari Tani farmer group can be implemented.

\section{CurcuMarvel Programme Socialization}

Socialization to the village apparatus and Sari Tani Farmer Group was carried out to explain the intended purpose of the CurcuMarvel program. The location of the socialization was in the Office of the Kiringan Village Head. The socialization focused on the awareness of the importance of understanding the level of soil acidity $(\mathrm{pH})$ and the efforts to rehabilitate the land independently and sustainably to increase the productivity of paddy fields. Documentation of the implementation of the socialization can be seen in Figure 2. 


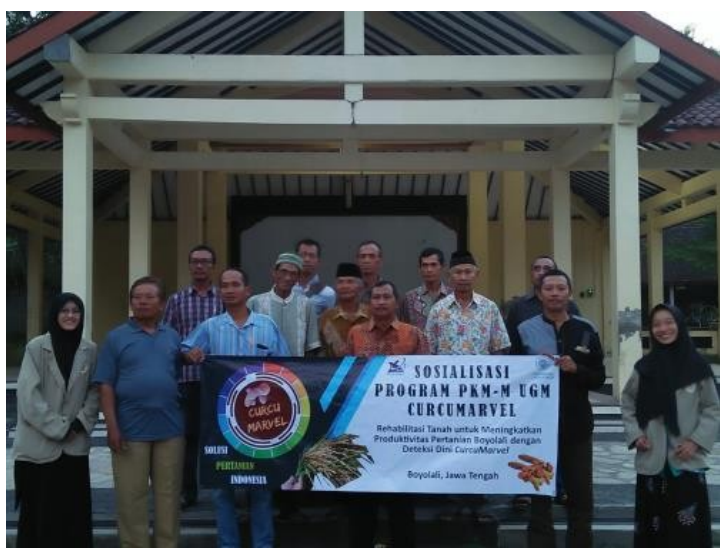

Figure 2. CurcuMarvel program sosialization

\section{Organizational Management}

Target farmers selected to participate in this empowerment program are subsequently appointed as administrators of the CurcuMarvel program. The formation of this management is intended to maintain the CurcuMarvel programs' sustainability even though the facilitator team is no longer assisting. The caretaker acts as a cadre who then trains all members of the Sari Tani Farmer Group. In the future, the Sari Tani farmer group will become a pioneer farmer group that can introduce turmeric as a simple alternative in detecting soil acidity in Boyolali. The program management structures consist of the chancellor, leader, secretary, treasurer, division guarantor soil $\mathrm{pH}$, soil rehabilitation division, the turmeric cultivation division, guidance, development division, and the information networks division, as depicted in Figure 3.

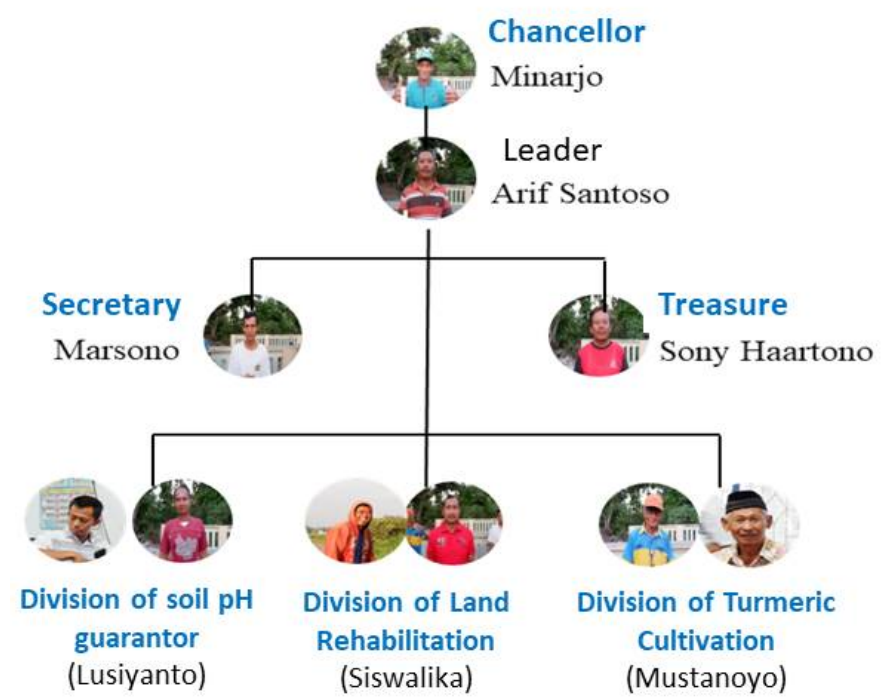

Figure 3. The organizational structure of CurcuMarvel program 


\section{Implementation of Activities}

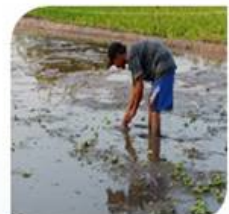

Take some the Soil sample

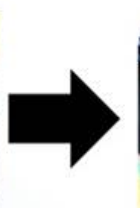

cut turmeric with a thickness of $0.25 \mathrm{~cm}$

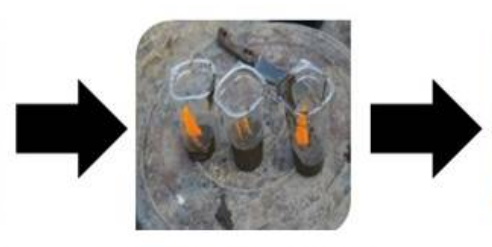

Turmeric is dipped in soil samples

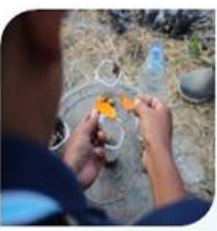

Seen changes in color

Figure 4. Techniques for measuring soil $\mathrm{pH}$

This activitys' primary goal is to educate the importance of the soils' acidity $(\mathrm{pH})$ and to play an educational video about the procedures for testing the acidity of the soil with turmeric. This stage is intended to grow awareness of the farmers in the Boyolali district, especially members of the Sari Tani farmers group, so they will have a willingness to rehabilitate the land. Figure 4 shows us the techniques use for measuring soil $\mathrm{pH}$. If the color of turmeric remains constant, it means the soil is neutral. How to determine the level of soil acidity is to see changes in the color of turmeric. If the shade change from yellow turns dark yellow, it means that the $\mathrm{pH}$ is more than 7 , which means the land tends to contained alkaline. The turmeric soil acidity results showed that the paddy soil in Suyudan was classified as an acid because the turmeric orange color faded, as shown in Figure 5.

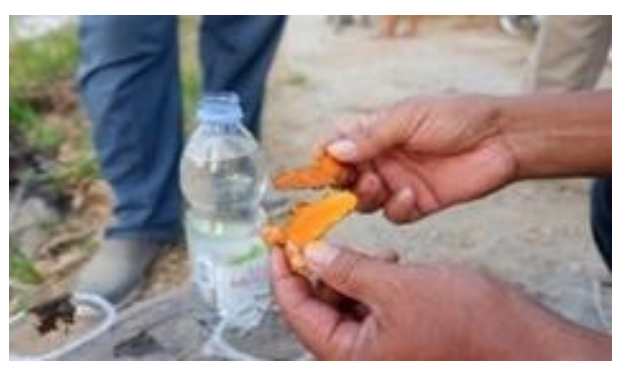

Figure 5. Soil acidity test with turmeric in Suyudan village

Figure 6 shows us the stage of the paddy soil rehabilitation process. The land identified in acidic conditions then further treated by spreading compost evenly on the soil and spraying biodiversity fertilizer that has been thawed. To make the turmeric plants with turmeric plant culture training, which can be used for detecting the acidity $(\mathrm{pH})$ of the soil of Suyudan hamlet farmers and other needs. A total of 15 turmeric seeds were distributed to cadres to be planted in the yard.

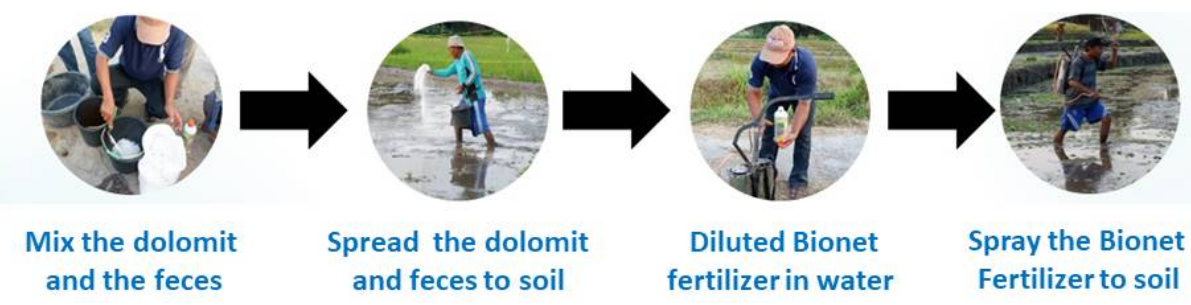

Figure 6. Soil rehabilitation process 


\section{Data Collection dan Result}

Table 1. Analysis of indicators of the success of the CurcuMarvel program in Suyudan village

\begin{tabular}{|c|c|c|}
\hline \multirow{2}{*}{ Criteria } & \multicolumn{2}{|r|}{ Analysis } \\
\hline & Before assistance & After assistance \\
\hline Knowledge & $\begin{array}{l}\text { Farmers do not know the importance of } \\
\text { soil acidity }\end{array}$ & $\begin{array}{l}\text { Increased knowledge and awareness of the } \\
\text { importance of soil acidity }\end{array}$ \\
\hline $\begin{array}{l}\text { Mental attitude and } \\
\text { awareness }\end{array}$ & $\begin{array}{l}\text { Farmers are not aware and do not care } \\
\text { that the rice fields need to be in acidic } \\
\text { condition }\end{array}$ & $\begin{array}{l}\text { Farmers have enthusiasm in utilizing turmeric } \\
\text { as an alternative measurement of the acidity of } \\
\text { rice field that is cheap and easy to obtain }\end{array}$ \\
\hline Skills & $\begin{array}{l}\text { Farmers do not have skills to } \\
\text { rehabilitate acidity of paddy soils }\end{array}$ & $\begin{array}{l}\text { "Sari Tani" farmer group applied how to detect } \\
\text { soil } \mathrm{pH} \text { with turmeric for farmers groups and } \\
\text { other Suyudan village farmers }\end{array}$ \\
\hline $\begin{array}{l}\text { The formation of local } \\
\text { community institutions }\end{array}$ & $\begin{array}{l}\text { There is no special section in the } \\
\text { organization that regulates the level of } \\
\text { soil acidity due to lack of awareness } \\
\text { about the level of soil acidity }\end{array}$ & $\begin{array}{l}\text { There is a formation of community groups as } \\
\text { activator for soil } \mathrm{pH} \text { detection and soil } \\
\text { rehabilitation }\end{array}$ \\
\hline Condition & $\begin{array}{l}\text { Paddy soil in acidic conditions. There is } \\
\text { no cultivation of turmeric in the yard of } \\
\text { the house }\end{array}$ & $\begin{array}{l}\text { Paddy soil in near neutral conditions. There is } \\
\text { turmeric cultivation in the farmer's yard }\end{array}$ \\
\hline Publication & $\begin{array}{l}\text { There is no publication about soil } \\
\text { acidity in Boyolali }\end{array}$ & $\begin{array}{l}\text { There are } 18 \text { popular publications from various } \\
\text { print and online media, and were registered in } \\
\text { the national agricultural socio-economic } \\
\text { seminar at Gadjah Mada University in } 2019\end{array}$ \\
\hline
\end{tabular}

\section{Monitoring and Evaluation of Program Implementation Sustainability}

The CurcuMarvel program team monitors the sustainability of program implementation through selected cadres. This empowerment program will prepare the cadre from active farmers to continuing the CurcuMarvel both inside and outside the Sari Tani farmer group. This empowerment program will prepare the cadre from active farmers to continuing the CurcuMarvel both inside or outside the Sari Tani farmer group.

This CurcuMarvel program runs $100 \%$ success. The level of satisfaction among farmers is very high since their paddy fields remain neutral, so productivity increases. Farmer's satisfaction can be seen from the enthusiasm of farmers to teach the same method to other farmers. The success indicators are knowledge, mental attitude, awareness, skills, the formation of local community institutions, condition, and publication. After the assistance, there has been some progress i.e. Increased knowledge and awareness of the importance of soil acidity, farmers have enthusiasm in utilizing turmeric as an alternative measurement of the acidity of paddy fields that is cheap and easy to obtain, "Sari Tani" farmer group applies how to detect soil ph with turmeric for farmers groups and other Suyudan village farmers, there is a formation of community groups as activator for soil ph detection and soil rehabilitation, paddy soil in near neutral conditions, there is turmeric cultivation in the farmer's yard, and there are 18 popular publications from various print and online media, and were registered in the National Agricultural Socio-Economic Seminar at Gadjah Mada University in 2019.

Based on the results of monitoring and evaluation of program implementation, the potential results are quite significant, including:

1. Empowering Communities with the CurcuMarvel Program

The CurcuMarvel program in Suyudan village can be disseminated through social media accounts such as Instagram to publish Suyudan village as a pioneering village of CurcuMarvel in order to give examples to other villages and also to the wider community the benefits of early detection of CurcuMarvel.

2. Community Knowledge in CurcuMarvel Early Detection and Soil Rehabilitation 
With the CurcuMarvel early detection training and how to apply it can increase the awareness of the community to conduct soil rehabilitation so that agricultural productivity increases.

3. Become a Sustainable Program

The establishment of the CurcuMarvel management division is intended to manage soil conditions and carry out soil rehabilitation and disseminate knowledge about CurcuMarvel's early detection so that agricultural productivity continues to increase. In addition, it is also intended to remain responsible for coordinating material purchases, scheduling early detection of CurcuMarvel, rehabilitating land, and applying it.

4. Made Products That Can Be Applied for The Community

The CurcuMarvel Program in Suyudan village can be used as a pioneer of Turmeric Early Detection of soil $\mathrm{pH}$ by the wider community. Turmeric is a natural indicator that can be used for soil $\mathrm{pH}$ detection and can be done not only in paddy fields, but also in plantation and garden lands. CurcuMarvel is an alternative $\mathrm{pH}$ detector that is sustainable, solutive, environmentally friendly and cheap in terms of price.

\section{CONCLUSION}

The CurcuMarvel program embodies the sustainability of agriculture in terms of soil fertility with the support of turmeric as a means of detecting soil acidity, which in the future can be harvested directly from each farmer's yard. This condition can support efforts to increase the productivity of the Sari Tani paddy group.

\section{REFERENCES}

[1] S. Maro'ah, Effect of soil characteristics and rainfall on paddy productivity in Bantul regency, Gadjah Mada University Press, Yogyakarta, 2014.

[2] T. Mardikanto, P. Soebianto, Community empowerment in revised edition public policy perspectives, Alfabeta, Bandung, 2012.

[3] E. Stahl, Analisa obat secara kromatografi dan mikroskopi, Institut Teknologi Bandung, Bandung, 1985.

[4] N.A. Nugroho, Manfaat dan prospek pengembangan kunyit, PT Trubus Agriwidya, Ungaran, 1998.

[5] S.J. Hewlings, D.S. Kalman, Curcumin: a review of its' effects on human health, Foods 6 (2017) 1-11.

[6] R. Rosmawani, M. Ahmad, J.M. Daud, The potential of curcumin reagent as a natural pH indicator for the development of an optical pH sensor, MJAS 11 (2007) 351-360. 